\title{
Group II innate lymphoid cells and microvascular dysfunction from pulmonary titanium dioxide nanoparticle exposure
}

\author{
Alaeddin Bashir Abukabda ${ }^{1,2}$, Carroll Rolland McBride ${ }^{1,2}$, Thomas Paul Batchelor ${ }^{1,2}$, William Travis Goldsmith ${ }^{1,2}$, \\ Elizabeth Compton Bowdridge ${ }^{1,2}$, Krista Lee Garner ${ }^{1,2}$, Sherri Friend ${ }^{3}$ and Timothy Robert Nurkiewicz ${ }^{1,2,3^{*}}$
}

\begin{abstract}
Background: The cardiovascular effects of pulmonary exposure to engineered nanomaterials (ENM) are poorly understood, and the reproductive consequences are even less understood. Inflammation remains the most frequently explored mechanism of ENM toxicity. However, the key mediators and steps between lung exposure and uterine health remain to be fully defined. The purpose of this study was to determine the uterine inflammatory and vascular effects of pulmonary exposure to titanium dioxide nanoparticles (nano- $\mathrm{TiO}_{2}$ ). We hypothesized that pulmonary nano- $\mathrm{TiO}_{2}$ exposure initiates a Th2 inflammatory response mediated by Group II innate lymphoid cells (ILC2), which may be associated with an impairment in uterine microvascular reactivity.
\end{abstract}

Methods: Female, virgin, Sprague-Dawley rats (8-12 weeks) were exposed to $100 \mu \mathrm{g}$ of nano- $\mathrm{TiO}_{2}$ via intratracheal instillation $24 \mathrm{~h}$ prior to microvascular assessments. Serial blood samples were obtained at 0, 1, 2 and $4 \mathrm{~h}$ post-exposure for multiplex cytokine analysis. ILC2 numbers in the lungs were determined. ILC2s were isolated and phosphorylated nuclear factor kappa-light-chain-enhancer of activated B cells (NF-kB) levels were measured. Pressure myography was used to assess vascular reactivity of isolated radial arterioles.

Results: Pulmonary nano-TiO 2 exposure was associated with an increase in IL-1B, 4, 5 and 13 and TNF- a 4 h postexposure, indicative of an innate Th2 inflammatory response. ILC2 numbers were significantly increased in lungs from exposed animals $(1.66 \pm 0.19 \%)$ compared to controls $(0.19 \pm 0.22 \%)$. Phosphorylation of the transactivation domain (Ser-468) of NF-KB in isolated ILC2 and IL-33 in lung epithelial cells were significantly increased (126.8 $\pm 4.3 \%$ and $137 \pm 11 \%$ of controls respectively) by nano- $\mathrm{TiO}_{2}$ exposure. Lastly, radial endothelium-dependent arteriolar reactivity was significantly impaired ( $27 \pm 12 \%)$, while endothelium-independent dilation $(7 \pm 14 \%)$ and a-adrenergic sensitivity ( $8 \pm 2 \%)$ were not altered compared to control levels. Treatment with an anti- IL-33 antibody (1 mg/kg) 30 min prior to nano- $\mathrm{TiO}_{2}$ exposure resulted in a significant improvement in endothelium-dependent dilation and a decreased level of IL-33 in both plasma and bronchoalveolar lavage fluid.

Conclusions: These results provide evidence that the uterine microvascular dysfunction that follows pulmonary ENM exposure may be initiated via activation of lung-resident ILC2 and subsequent systemic Th2-dependent inflammation.

Keywords: Engineered nanomaterials, Titanium dioxide nanoparticles, Microcirculation, Innate lymphoid cells, Inflammation

\footnotetext{
* Correspondence: tnurkiewicz@hsc.wvu.edu

'Department of Physiology and Pharmacology, West Virginia University

School of Medicine, 64 Medical Center Drive, Robert C. Byrd Health Sciences

Center - West Virginia University, Morgantown, WV 26505-9229, USA

${ }^{2}$ Toxicology Working Group, West Virginia University School of Medicine,

Morgantown, WV, USA

Full list of author information is available at the end of the article
}

(c) The Author(s). 2018 Open Access This article is distributed under the terms of the Creative Commons Attribution 4.0 International License (http://creativecommons.org/licenses/by/4.0/), which permits unrestricted use, distribution, and reproduction in any medium, provided you give appropriate credit to the original author(s) and the source, provide a link to the Creative Commons license, and indicate if changes were made. The Creative Commons Public Domain Dedication waiver (http://creativecommons.org/publicdomain/zero/1.0/) applies to the data made available in this article, unless otherwise stated. 


\section{Introduction}

Reproductive toxicity is increasingly becoming recognized as a critical aspect of ENM safety. However, the effects of ENM exposure on overall reproductive health have only recently been addressed and become a focus of intense study by numerous groups [1, 2]. As with other observations of systemic biologic effects after pulmonary ENM exposures, reproductive effects are equally susceptible but poorly understood. Our group has previously reported that nano- $\mathrm{TiO}_{2}$ inhalation is associated with uterine microvascular dysfunction [3], potentially deleterious epigenomic alterations [4], and cognitive deficits in maternally exposed progeny [5]. While these studies highlight the importance of identifying the maternal effects of ENM exposure, the mechanisms linking such exposures to these negative reproductive and developmental outcomes have yet to be fully elucidated.

In the last decade, innate lymphoid cells (ILC) have emerged as a novel population of tissue-specific effector cells with the ability to initiate and regulate the innate and adaptive branches of the immune system [6, 7]. ILCs are now divided into 3 distinct groups according to the pattern of cytokine secretion; Group 1 ILC (ILC1) are predominantly tissue-resident cells capable of secreting interferon gamma (IFN- $\gamma$ ) in the liver, gut, spleen, skin, peritoneum, and salivary gland [8]. The role played by ILC1 in various immunological conditions remains unclear but is currently under investigation. Group 2 ILCs (ILC2, also known as nuocytes, natural helper cells) secrete IL-4, IL-5, IL-9, and IL-13 in response to damage-associated molecular patterns or "alarmins" and have been implicated in the immune response to parasitic infections and in allergic airway inflammation [9] to several environmental and anthropogenic agents [10, 11]. Lastly, group 3 ILCs (ILC3) produce IL-22 and or IL-17, are enriched at mucosal sites, contribute to the maintenance of the intestinal barriers, and may play a significant role in the promotion of the inflammatory response and etiology of inflammatory bowel diseases $[12,13]$. One of the most important alarm signals secreted by cells is interleukin-33 (IL-33) [14]. IL-33 is a member of the IL-1 family of cytokines expressed by both non-immune cells such as epithelial, endothelial, smooth muscle cells, and fibroblasts [15], as well as immune effector cells including macrophages and dendritic cells. Its role in directing the inflammatory response following pulmonary exposure to carbon nanotubes [16-18], and ozone [19] have been previously reported. IL-33 has been demonstrated [20] to induce the release of Th2 cytokines by immune cells including ILC2s in asthmatic patients [21], and to induce airway hyperresponsiveness and increased pulmonary resistance [22, 23].

In view of the increasing number of studies indicating a crucial role for ILCs in the initiation of the acute inflammatory response to environmental agents, the goal of this work was to provide initial evidence of their potential involvement in the response to pulmonary ENM exposure. Therefore, the purpose of this study was threefold. First, we identified the inflammatory and uterine microvascular effects associated with acute pulmonary nano- $\mathrm{TiO}_{2}$ exposure. Second, we determined the possible role played by ILC in the immune response mounted to acute pulmonary nano- $\mathrm{TiO}_{2}$ exposure. Lastly, the microvascular and systemic effects of treatment with an IL-33 antibody (a key activator of ILC2) were determined. We hypothesized that pulmonary nano- $\mathrm{TiO}_{2}$ exposure initiates a Th2 inflammatory response mediated involving IL-33 and potentially involving ILC2, which may be associated with a systemic impairment in uterine microvascular reactivity.

\section{Results}

SEM images and mass spectrometry of $\mathrm{Nano}^{-\mathrm{TiO}_{2}}$

Figure 1 shows field-emission scanning electron microscope images (Hitachi S4800, Tokyo, Japan) of the nano- $\mathrm{TiO}_{2}$ suspension used for this study. As seen in Fig. 1a, the suspended particles present significant agglomeration. Figure 1b shows the elemental composition of the nano- $\mathrm{TiO}_{2}$ suspension (Bruker, Billerica, MA), indicating the prevalent presence of titanium.

\section{Animal and vessel characteristics}

No significant changes were observed in age, mean arterial pressure (MAP), heart rate and body weight between control and exposure groups (Table 1). Additionally, radial arteriolar inner and outer diameter, tone, passive diameter, wall thickness, wall to lumen ratio and calculated wall tension were not affected by nano- $\mathrm{TiO}_{2}$ exposure and treatment with an anti-IL-33 antibody (Table 2). From these results we can infer that acute nano- $\mathrm{TiO}_{2}$ exposure does not alter vascular tone or the balance of its contributing influences.

\section{Acute plasma and BALF cytokine secretion patterns following pulmonary Nano- $\mathrm{TiO}_{2}$ exposure}

A time-course study was initially performed to identify the temporal effect of nano- $\mathrm{TiO}_{2}$ on cytokine secretion. Plasma samples were obtained at $0,1,2$, and $4 \mathrm{~h}$ following nano- $-\mathrm{TiO}_{2}$ exposure by tail vein puncture. Figure 2 shows the results of the multiplex analysis. No differences existed at time 0,1 or $2 \mathrm{~h}$ post-exposure. However, significant differences were detected $4 \mathrm{~h}$ post-exposure in plasma levels of the pro-inflammatory cytokines IL-4, IL-5, IL-13, TNF- $\alpha$, IL- $1 \beta$, while no alterations in the cytokines IFN- $\gamma, \mathrm{KC} /$ GRO, TNF- $\alpha$, IL-10, IL-6, MCP-1, TIMP-1, Lipocalin-2, and TSP-1 were noted (Data not shown).

In order to confirm the results observed in the plasma, the cytokine levels in the BALF were also measured $4 \mathrm{~h}$ post-exposure. Multiplex analysis of the BALF (Fig. 3) 
A

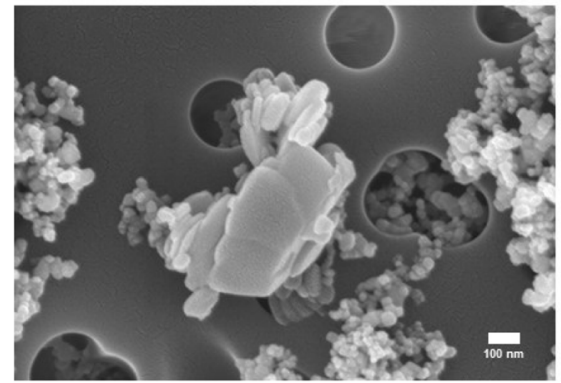

B

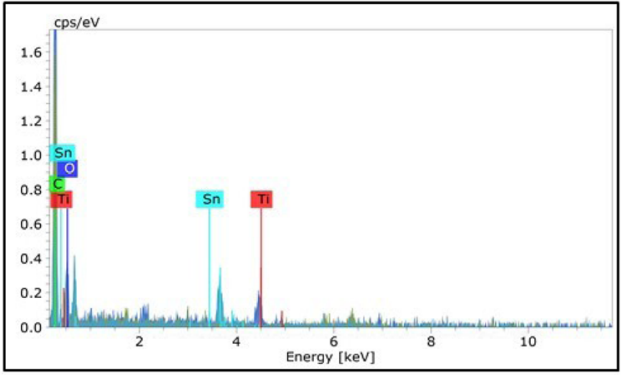

Fig. 1 Characterization of $\mathrm{Nano}^{-\mathrm{TiO}_{2}}$. (a) SEM image and (b) Energy dispersive spectroscopy showing elemental composition of the nano-TiO 2 suspension used in this study

also showed an almost 5-fold increase in IL-5 and a 6-fold increase in IL-4, IL-13, TNF- $\alpha$, and IL-1 $\beta$, while no changes were seen in the other cytokines (Data not shown). Based on the collective cytokine profile associated with this exposure paradigm, the results provide evidence that acute pulmonary nano- $\mathrm{TiO}_{2}$ exposure may trigger a T-Helper cell type 2 (Th2) response beginning 4 h post-exposure.

\section{IL-33 secretion by lung epithelial cells pre- and post- exposure and following treatment with an anti-IL-33 antibody}

IL-33 plays a significant role in initiating and modulating lung inflammatory and immunological responses [24], by inducing the secretion of Th2 pro-inflammatory cytokines. It is constitutively present in mucosal epithelial cells and acts as a "danger" signal after tissue injury by activating immune cells. To determine the effect of nano- $\mathrm{TiO}_{2}$ on pulmonary and plasma IL-33 levels, immunohistochemistry of tracheal sections was conducted $4 \mathrm{~h}$ post-exposure. In a separate cohort of control and exposed animals, multiplex analysis of plasma and BALF IL-33 was also performed $4 \mathrm{~h}$ post-exposure. Figure 4 shows representative images of lung sections from control and exposed rats stained for IL-33 $4 \mathrm{~h}$ post-exposure and the quantitative measurements for both groups. Relative fluorescence intensity of IL-33 was significantly increased in exposed animals by $26.8 \pm$ $4.3 \%$, while plasma and BALF levels indicated a $37.87 \pm$ $2.3 \%$ and $171.26 \pm 13 \%$ increase in IL-33 respectively (Fig. 5). Interestingly, treatment $1 \mathrm{~h}$ prior to exposure to nano- $\mathrm{TiO}_{2}$ with pharmacological grade polyclonal anti-IL-33 antibody (EMD Millipore, Temecula, CA: intraperitoneal $1 \mathrm{mg} / \mathrm{kg}$ ) resulted in a decrease in plasma and BALF IL-33 levels $4 \mathrm{~h}$ post-exposure $(61.1 \pm 2.1 \%$ in plasma and $149.7 \pm 7 \%$ in BALF) when compared to nano- $\mathrm{TiO}_{2}$ exposed and untreated animals. The results herein described provide evidence that reveals the critical role played by IL-33 in the initiation of the inflammatory response to ENM.

\section{Flow cytometric analysis of ILC1 and ILC2}

Polarization of T-cells requires several days [25], therefore, the early appearance of Th2 cytokines in the circulation after nano- $\mathrm{TiO}_{2}$ suggests that other, more rapid immune effector cells may be involved. Previous work has indicated that both ILC1 and ILC2 $[26,27]$ reside in the lungs and may be involved in lung inflammatory responses and pathology. Therefore, we next wanted to determine the effect of nano- $-\mathrm{TiO}_{2}$ exposure on ILC1 and ILC2 levels in the lungs. For this reason, multi-parametric flow cytometric analysis was conducted on lung tissue from control and nano- $\mathrm{TiO}_{2}$ exposed Sprague-Dawley rats for ILC1 (Data not shown) and ILC2 (Fig. 6) 4 h post-exposure. No significant differences were noted in ILC1 levels pre- and post- exposure while ILC2 levels increased from $0.19 \pm 0.22 \%$ to $1.66 \pm 0.19 \%$ (Fig. 7a and b).

\section{NF-KB phosphorylation and Th2 cytokine secretion by isolated ILC2}

Activation of the NF- $\mathrm{KB}$ pathway has been shown to play a role in inflammation through its ability to induce the transcription of proinflammatory genes [28, 29]. Specifically, phosphorylation of $\mathrm{NF}-\mathrm{kB}$ at both serine residues 468 and 536 are associated with inflammatory response $[29,30]$. Therefore, levels of phospho- $\mathrm{NF}-\mathrm{kB}$ were measured in isolated ILC2 from control and nano- $-\mathrm{TiO}_{2}$

Table 1 Animal characteristics

\begin{tabular}{|c|c|c|c|c|c|c|c|}
\hline & $\mathrm{N}$ & Age (weeks) & weight (grams) & Heart Rate (bpm) & Map $(\mathrm{mm} \mathrm{Hg})$ & Systolic Blood pressure $(\mathrm{mm} \mathrm{Hg})$ & Diastolic Blood Pressure $(\mathrm{mm} \mathrm{Hg})$ \\
\hline Control & 13 & $14 \pm 1$ & $232 \pm 5$ & $319 \pm 13$ & $85 \pm 3$ & $103 \pm 4$ & $73 \pm 2$ \\
\hline Exposed & 14 & $15 \pm 1$ & $249 \pm 12$ & $330 \pm 9$ & $86 \pm 4$ & $110 \pm 6$ & $78 \pm 4$ \\
\hline
\end{tabular}

Table showing characteristics of control $(N=13)$ and exposed groups $(N=14)$. Values shown are mean \pm SEM. Statistics were analyzed with two-way ANOVA $(P \leq 0.05),{ }^{*}$ Sham control group vs. nano- $\mathrm{TiO}_{2}$ exposed groups 
Table 2 Arteriolar characteristics

\begin{tabular}{llllllll}
\hline & $\mathrm{n}$ & Inner diameter $(\mu \mathrm{m})$ & Outer diameter $(\mu \mathrm{m})$ & Tone $(\%)$ & $\begin{array}{l}\text { Passive diameter } \\
\text { inner }(\mu \mathrm{m})\end{array}$ & $\begin{array}{l}\text { Passive diameter } \\
\text { outer }(\mu \mathrm{m})\end{array}$ & $\begin{array}{l}\text { Wall Tension } \\
(\text { Newton/meter })\end{array}$ \\
\hline Control & 18 & $98 \pm 5$ & $152 \pm 14$ & $26 \pm 7$ & $152 \pm 9$ & $199 \pm 15$ & $0.33 \pm 0.1$ \\
Exposed & 16 & $102 \pm 11$ & $164 \pm 13$ & $21 \pm 4$ & $159 \pm 15$ & $207 \pm 17$ & $0.34 \pm 0.1$ \\
Exposed + anti-L-33 & 12 & $97 \pm 11$ & $158 \pm 19$ & $21 \pm 4$ & $140 \pm 14$ & $187 \pm 26$ & $0.31 \pm 0.6$ \\
\hline
\end{tabular}

Table showing characteristics of control and exposed radial arterioles $(n=12-18)$. All vascular assessments were performed $24 \mathrm{~h}$ post-exposure. Values shown are mean \pm SEM. Statistics were analyzed with two-way ANOVA $(\mathrm{P} \leq 0.05),{ }^{*}$ Sham control group vs. nano-TiO ${ }_{2}$ exposed groups

exposed animals (Fig. 8). No significant differences were noted in phosphorylation of the Serine-536 residue between the 2 groups, while phosphorylation of Serine-468 was increased after acute pulmonary nano- $\mathrm{TiO}_{2}$ exposure $(128.6 \pm 7.24 \%$ of control levels $)$.

Lastly, isolated ILC2 were cultured overnight and IL-4, IL-5 and IL-13 levels in the cell-culture media were measured. Nano- $\mathrm{TiO}_{2}$ resulted in a significant increase in IL-4, IL-5, and IL-13 (122 $\pm 7.2 \%, 141.4 \pm 9.1 \%, 158.8 \pm 7.6 \%$ of control levels respectively) (Fig. 9).

\section{Effect of acute pulmonary $\mathrm{Nano}^{-\mathrm{TiO}_{2}}$ exposure and systemic immunotherapy on uterine radial arterioles Endothelium-dependent dilation}

In order to identify the acute reproductive effects associated with nano- $\mathrm{TiO}_{2}$ exposure, radial arterioles were isolated from the uterus of control and exposed animals $24 \mathrm{~h}$ post-exposure and endothelium-dependent and independent dilation along with adrenergic sensitivity were tested. Previous work by our group has shown that ENM exposure impacts vascular reactivity most severely within $24 \mathrm{~h}$, a condition which has been shown to improve but not fully return to control levels after $168 \mathrm{~h}$ [30]. Based on these findings, all vascular assessments for this study were conducted $24 \mathrm{~h}$ postexposure.

Endothelium-dependent dilation of radial arterioles was significantly impaired following intratracheal instillation of $100 \mu \mathrm{g}$ of nano- $\mathrm{TiO}_{2}$ (Fig. 10), with a mean decrease in dilation of $49.23 \pm 6.5 \%$ compared to controls and $24.35 \pm 10 \%$ compared to anti-IL-33 antibody-treated rats. These results suggest that pulmonary nano- $\mathrm{TiO}_{2}$ exposure disrupts normal physiological vascular endothelial function and that pre-treatment with an anti-IL-33 antibody partially attenuates the systemic acute inflammatory cascade triggered by lung-derived IL-33.

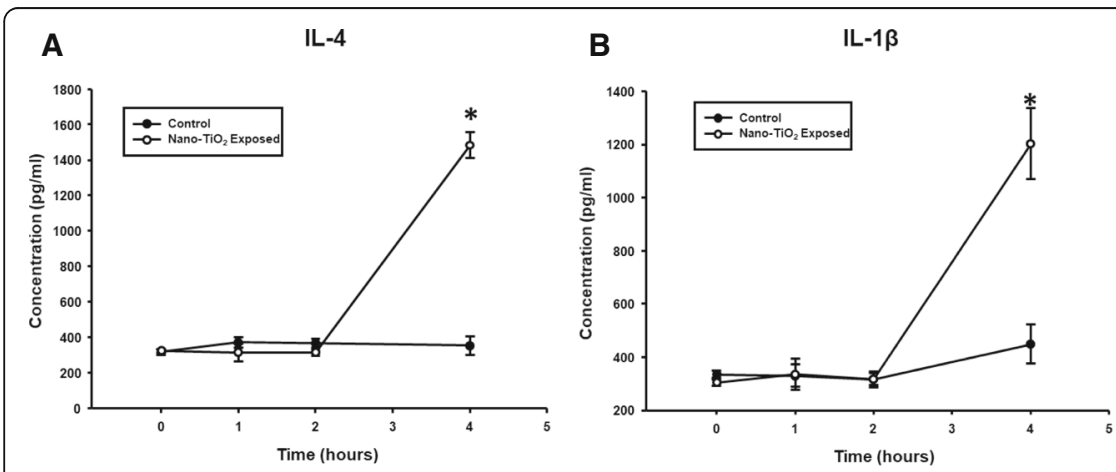

C TNF- $\alpha$

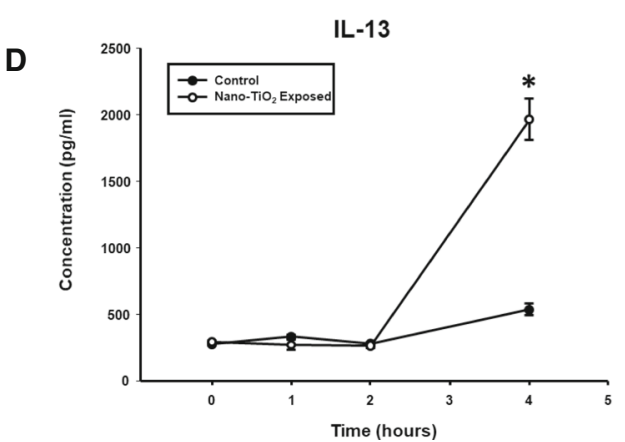

E

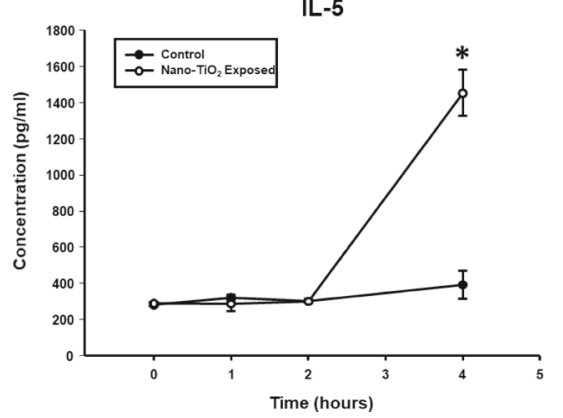

Fig. 2 Nano- $\mathrm{TO}_{2}$ exposure increases T-Helper type II cytokines $4 \mathrm{~h}$ post-exposure. Multiplex cytokine analysis showing concentrations of IL-4 (a), IL-1 $(\mathbf{b}$ ), TNF-a (c), IL-13 (d) and IL-5 (e). Serum samples were obtained at 0, 1, 2 and $4 \mathrm{~h}$ post-exposure via tail-vein puncture $(N=6)$. Statistics were analyzed with two-way ANOVA $(P \leq 0.05)$, * Sham control group vs. nano-TiO 2 exposed groups 


\section{Broncholalveolar Lavage}

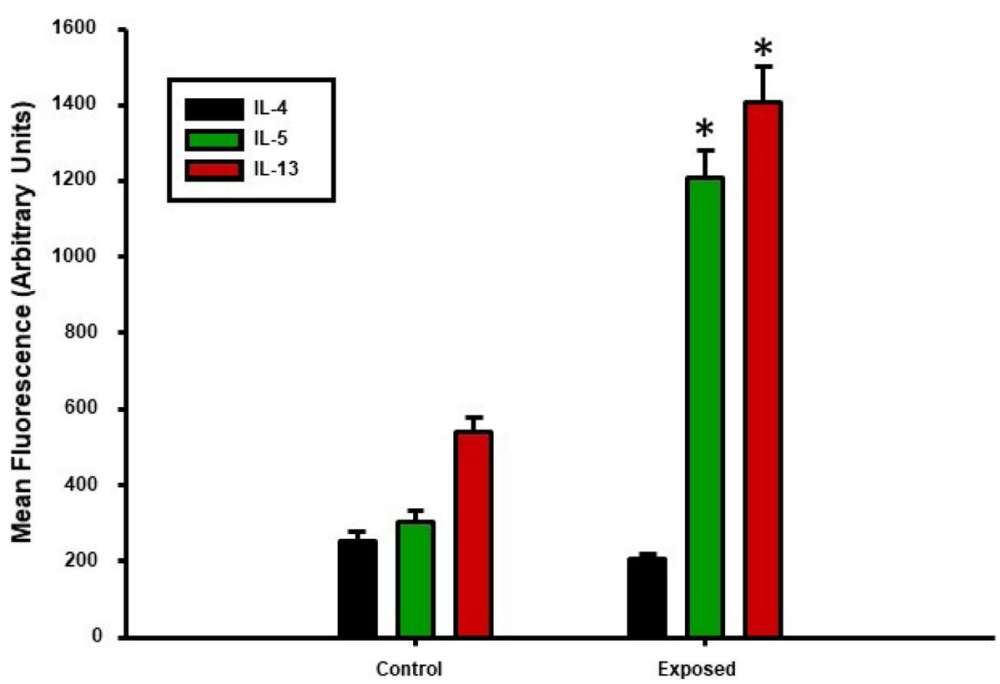

Fig. $3 \mathrm{Nano}-\mathrm{TiO}_{2}$ exposure also increases T-Helper type II cytokines $4 \mathrm{~h}$ post-exposure in bronchoalveolar lavage fluid (BALF). Multiplex cytokine analysis showing concentrations of IL-4, IL-5, IL-13 in BALF from exposed and control animals $4 \mathrm{~h}$ post-exposure $(N=6)$. Statistics were analyzed with two-way ANOVA $(P \leq 0.05), *$ Sham control group vs. nano- $\mathrm{TiO}_{2}$ exposed groups

In contrast to endothelium-dependent relaxation, no point to point differences were seen in $\alpha$-adrenergic and endothelium-independent dilation between control, nano$\mathrm{TiO}_{2}$ exposed, and treated groups (Data not shown).

\section{Discussion}

The inflammatory paradigm tested herein has been suggested by previous studies [16, 31, 32]. While these studies explored pulmonary responses to exogenously administered IL-33, carbon nanotubes and viral infection, our findings provide additional evidence of a similar link between acute pulmonary ENM exposure and subsequent inflammatory mechanisms with systemic microvascular consequences. Perhaps the most important finding of this study is the identification of IL-33 as a potential contributor to the systemic inflammatory phenotype and microvascular dysfunction resulting from acute pulmonary ENM exposure.
A

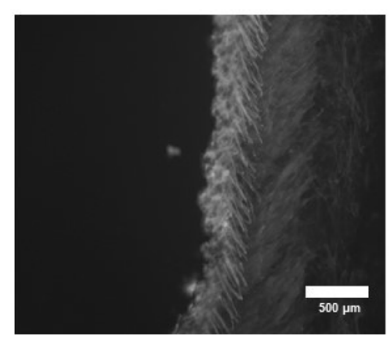

$\mathbf{B}$

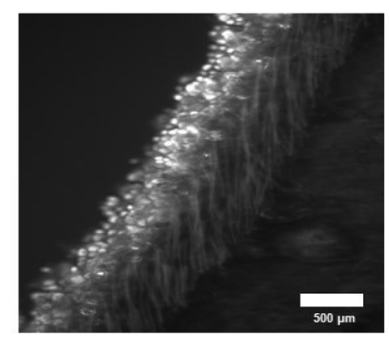

C

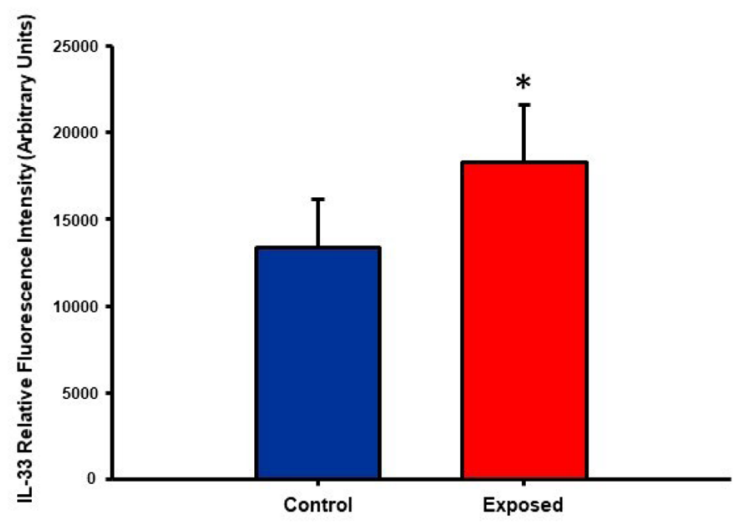

Fig. 4 Nano- $\mathrm{TiO}_{2}$ exposure is associated with an increase in pulmonary interleukin-33 levels. Lung sections from control (a) and nano-TiO 2 exposed (b) animals obtained $4 \mathrm{~h}$ post-exposure were stained for interleukin-33. Fluorescence was achieved by staining tracheal sections with an anti-IL-33-FITC conjugated antibody. Relative fluorescence is shown in (c) tagged antibody ( $N=6-7)$. Statistics were analyzed with two-way ANOVA $(P \leq 0.05),{ }^{*}$ Sham control group vs. nano- $\mathrm{TiO}_{2}$ exposed groups 

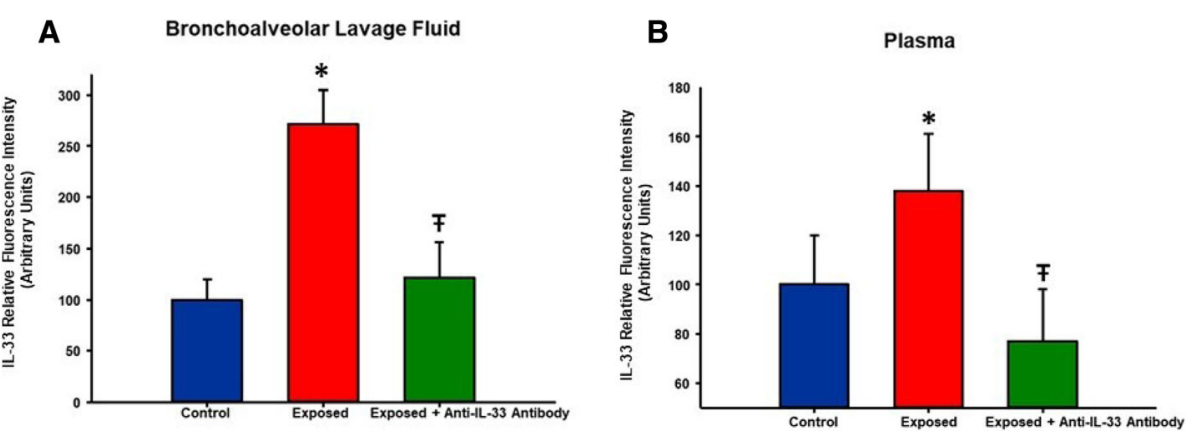

Fig. 5 Pre-treatment of nano-TiO 2 - exposed animals with an anti-IL-33 antibody lowers BALF and plasma IL-33. Interleukin-33 levels in (a) BALF and (b) plasma in control, nano- $\mathrm{TiO}_{2}$ exposed groups and in rats pre-treated with an anti-IL-33 antibody. Rats were pre-treated with an anti-IL-33 antibody (1 mg/kg) $30 \mathrm{~min}$ prior to exposure. Plasma and BALF IL-33 levels were measured $4 \mathrm{~h}$ post-exposure. Statistics were analyzed with two-way ANOVA $(P \leq 0.05)$. * Sham control group vs. nano- $\mathrm{TiO}_{2}$ exposed groups, $\mp P<0.05$ Exposed + Anti-IL-33 Antibody vs Exposed

We hypothesized that the innate response to pulmonary nano- $\mathrm{TiO}_{2}$ exposure is triggered by the secretion of IL-33 by lung epithelial cells. IL-33, a member of the IL-1 family, plays a significant role in initiating and modulating lung inflammatory and immunological responses [33], by inducing the secretion of Th2 pro-inflammatory cytokines through the Suppression of Tumorigenicity 2 (ST2) receptor in a variety of immune cells [32, 34]. Previous studies have shown that exposure to multi-walled carbon nanotubes triggers the IL-33/ST2 axis leading to the activation of mast-cells and macrophages [20]. Interestingly, IL-33 is also required for the maturation, activation and egress of ILC2 lineage cells from the bone marrow to specific target organs [35]. Several previous studies by our group and others have extensively investigated the cardiovascular effects of pulmonary ENM exposure [36, 37]. These studies consistently reveal that nano- $\mathrm{TiO}_{2}$ exposure increases leukocyte activation [38], proinflammatory mediators [39], and oxidative stress [40]. Collectively, this results in endothelium-dependent dysfunction. ILCs are a recently identified subpopulation of immune effector cells [33, 41]. They are critical, non-cytolytic tissue-resident cells that can be activated and respond acutely to danger signals or "alarmins" such as IL-33 from mucosal tissue by producing a distinctive array of cytokines to maintain mucosal integrity. Group II ILCs specifically, secrete the cytokines

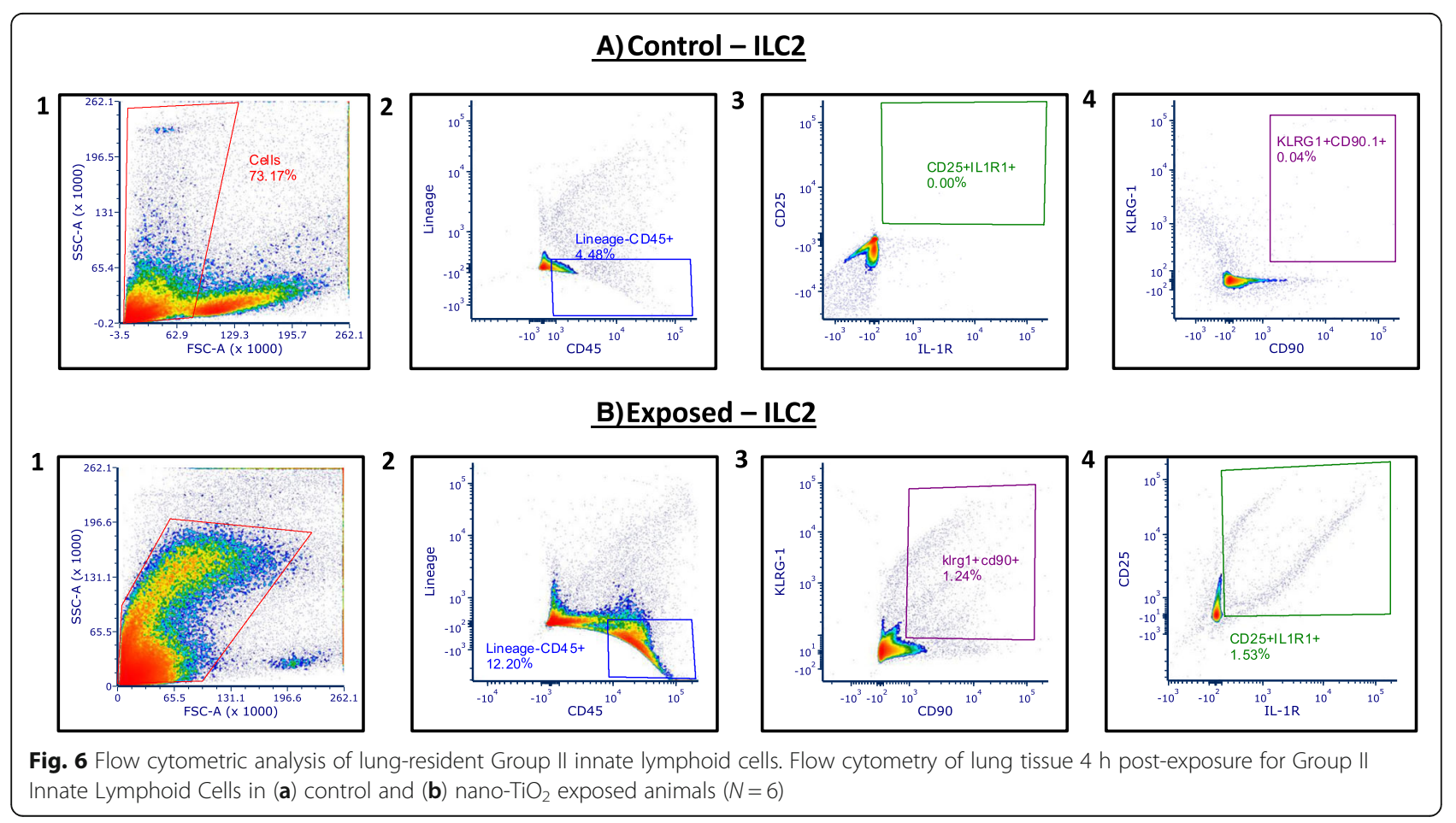



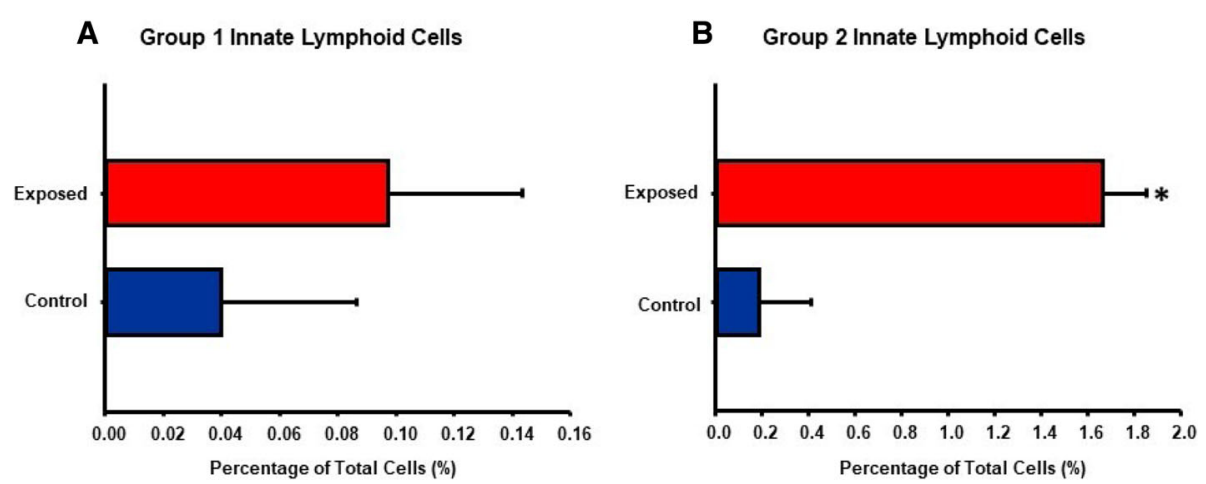

Fig. 7 Nano-TiO 2 exposure increases pulmonary ILC2 but not ILC1. Quantification of percentage of total pulmonary cells of (a) ILC1 and (b) ILC2 in control and nano- $\mathrm{TiO}_{2}$ exposed animals $(\mathrm{N}=6)$. Statistics were analyzed with two-way ANOVA $(P \leq 0.05)$, * Sham control group vs. nano-TiO 2 exposed groups

IL-5, IL-13, IL-9, amphiregulin, and low quantities of IL-4 [31] and have been linked to several lung-associated conditions including pathogen infections (viruses and helminths), asthma, and pulmonary fibrosis [42]. Lung ILC2 have an important role in regulating tissue remodeling and repair during acute epithelial injury and asthma [43]. Considered together, it is reasonable to speculate that the IL-33/ILC2 axis may impact systemic microvascular function after pulmonary ENM exposure.

Perhaps, the most significant finding of this study is the identification of a potential role for IL-33 in the initiation of an acute inflammatory response and the effects on systemic microvascular dysfunction (Fig. 10). This was achieved by interrupting the IL-33/ST2 signaling axis with an anti-IL-33 antibody treatment prior to ENM exposure. In these experiments, the control group (IT saline) did not receive the anti-IL-33 antibody. The scientific rationale for this decision was that the technique (isolated, perfused and pressurized arterioles) used to assess microvascular dysfunction is a plasma free system. As such, it was impossible to assess the role of the complete IL-33/ST2 axis on arteriolar tone and/or reactivity. Whereas, this approach directly measured the impact that IL-33 inflammatory signaling has on microvascular function. It remains a distinct possibility that the IL-33/ST2 axis activated by pulmonary ENM exposure directly influences microvascular tone and/or reactivity. IL-33 expression has been identified in human vascular endothelial cells; whereas, is absent in murine vascular tissue [44]. This supports our postulate that IL-33 is impacting microvascular function via inflammation, rather than a direct activation of the ST2 receptor. Future in vivo studies must directly assess the impact of circulating IL-33 on microvascular tone, reactivity and blood flow.

While our study provides plausible mechanistic insights into both the inflammatory and microvascular effects associated with ENM exposure, additional considerations as well as the limitations must be kept in mind. ENM exposure has been shown to affect other innate immune effector cells such as neutrophils $[45,46]$, macrophages [47, 48], and dendritic cells [49]. Therefore, other mechanisms including local generation of reactive of oxygen species, secretion of chemokines and prostaglandins by macrophages and stimulation of the adaptive immune system by antigen-presenting cells
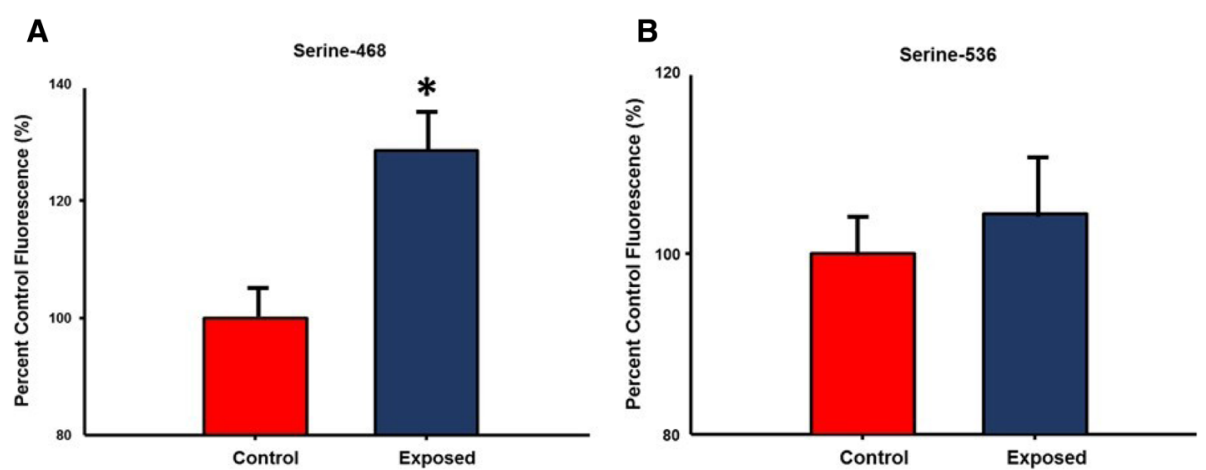

Fig. 8 Nano-TiO 2 exposure increases NF-KB phosphorylation at Serine-468 in isolated ILC2. Quantification of NF-KB phosphorylation at (a) serine468 and (b) serine 536 in isolated ILC2 from isolated. ILC2 from control and nano-TiO 2 exposed animals $(\mathrm{N}=6)$. Statistics were analyzed with twoway ANOVA $(\mathrm{P} \leq 0.05)$, * Sham control group vs. nano- $\mathrm{TiO}_{2}$ exposed groups 


\section{Cell Supernatant}

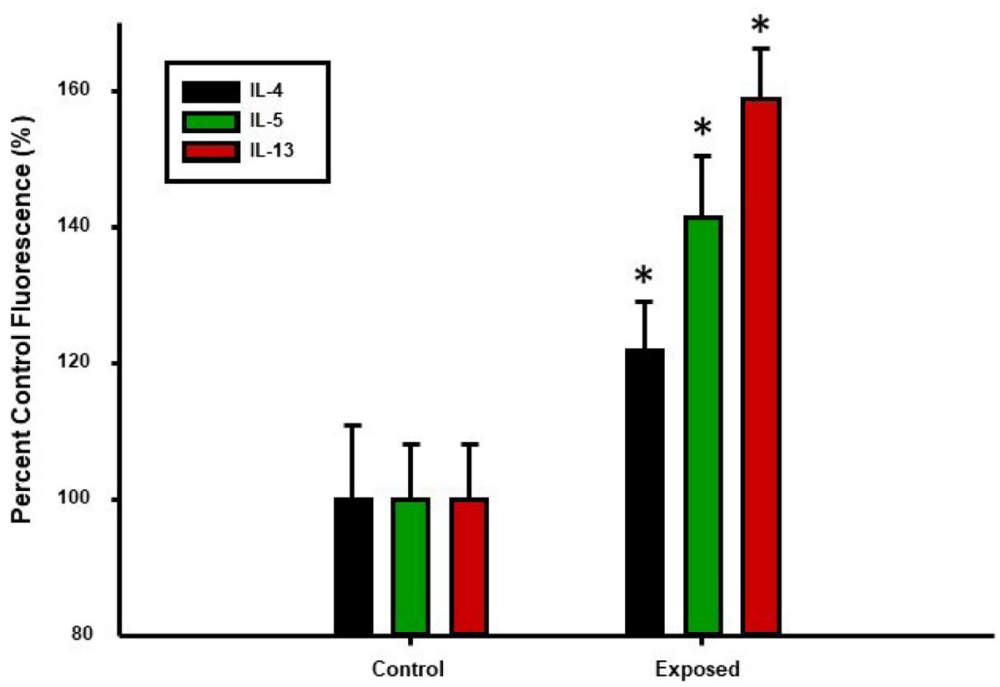

Fig. 9 Th2 cytokine secretion in isolated ILC2 is increased by nano- $\mathrm{TiO}_{2}$ exposure. Multiplex cytokine analysis showing concentrations of IL-4, IL-5, IL-13 supernatant from isolated ILC2 cultured overnight from control and nano- $\mathrm{TiO}_{2}$ exposed animals $(\mathrm{N}=6)$. Statistics were analyzed with two-way ANOVA $(P \leq 0.05)$, * Sham control group vs. nano- $\mathrm{TiO}_{2}$ exposed groups

may play a role in the systemic inflammatory response and vascular effects seen in this study. It is also worth noting that in this study an immune response associated with pulmonary ENM exposure was observed as early as $4 \mathrm{~h}$ post-exposure, as evidenced not only by an increase in the proportion of lung-resident ILC2s (Fig. 7), but also by augmented levels of the Th2 cytokines IL-4, IL-5, and IL-13 (Figs. 2 and 3). This response timeframe is in agreement with previous studies, that have reported IL33, ILC2 numbers as well as lung and serum Th2 cytokines increase within $6-12 \mathrm{~h}$ of lung injury $[50,51]$. Furthermore, isolated ILC2s have been shown to respond dose-dependently to transient or continuous stimulation with IL-2 and/or IL-33 within $3 \mathrm{~h}$ [52]. Similarly, nano- $\mathrm{TiO}_{2}$ instillation at lung burdens of $40-160 \mu \mathrm{g} /$ rat has also been shown to increase BALF inflammatory mediators within $4 \mathrm{~h}$ of exposure [53].

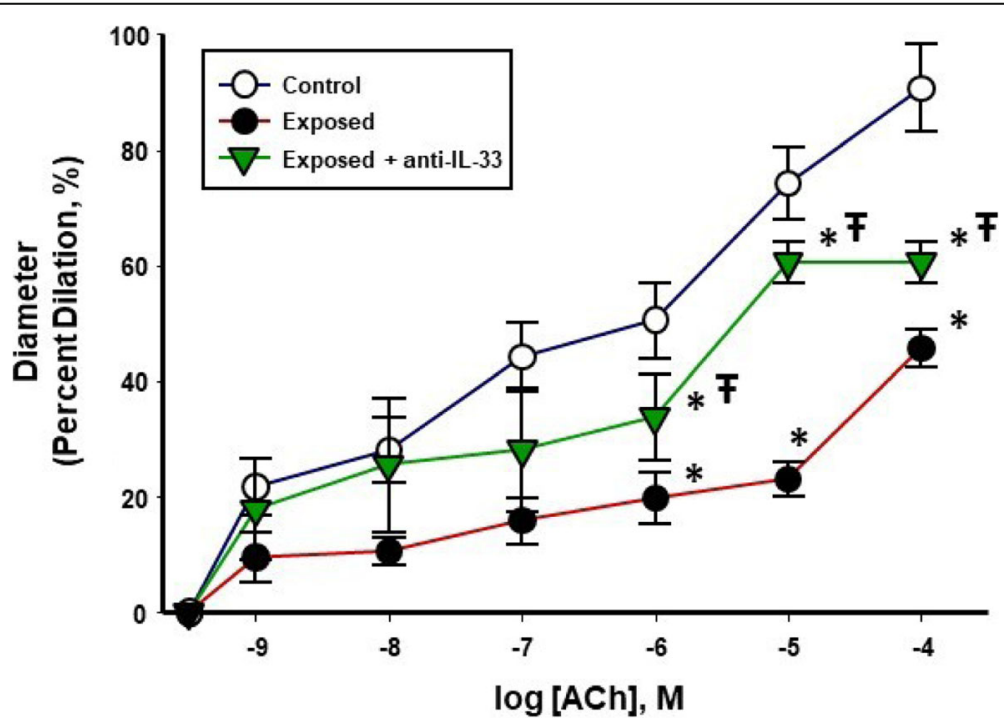

Fig. 10 Endothelium-dependent dilation of radial arterioles is blunted by nano- $\mathrm{TiO}_{2}$ exposure and improved by pre-treatment with an anti-IL-33 antibody. Endothelium-dependent dilation of uterine radial arterioles from control, exposed and anti-IL-33 antibody treated animals was determined using pressure myography $(n=12-18)$. All vascular assessments were performed $24 \mathrm{~h}$ post-exposure. Statistics were analyzed with two-way ANOVA $(P \leq 0.05)$. * Sham control group vs. nano-TiO 2 exposed groups, $\mp P<0.05$ Exposed + Anti-lL-33 Antibody vs Exposed 
We report herein a similar phenomenon as the lung burden used in this study was comparable at $100 \mu \mathrm{g} / \mathrm{rat}$.

Our findings contribute consistent evidence for a role of ILC2s in the acute pulmonary response to ENM exposure. Due to the inherent limitations associated with our experimental in vivo model, we were unable to directly establish causality. In order to directly confirm such an observation, ILC2 deletion would be necessary. Our research program has a long-standing interest in the systemic microvascular consequences of pulmonary particle exposure. Rat models are primarily used in our in vivo studies as they are the most appropriate and widely used animals for microvascular research. However, they are not commonly or easily adapted for transgenic studies. As such, an ILC2 rat deletion model does not exist. If such a model were created in the future, it would then be possible to directly confirm a causative relationship between ENM exposure and ILC2 activation, proliferation and recruitment.

Lastly, to allow periodic blood sampling for cytokine analysis, intratracheal instillation was chosen as the preferred exposure method. The above-mentioned dose of nano- $\mathrm{TiO}_{2}$ was selected based on previous studies conducted by our group which have shown that it is associated with significant microvascular impairment, oxidative and nitrosative stress and alveolar macrophage recruitment $[36,54]$. Additionally, to better understand the relevance of the exposure paradigm used in this study to humans, alveolar surface areas must be known [55]. The rat alveolar surface area is $0.4 \mathrm{~m}^{2} /$ lung. Therefore, the rat burden of $50 \mu \mathrm{g} / \mathrm{lung}$ would result in $125 \mu \mathrm{g} / \mathrm{m}^{2}$. Given that the human alveolar surface area is $102 \mathrm{~m}^{2}$, the equivalent human burden of this exposure paradigm would be $12.75 \mathrm{mg}$. The next logical question is: How long would it take to achieve this burden in humans? In this regard, lung burden may be calculated as:

nano-TiO $\mathrm{O}_{2}$ aerosol concentration - minute ventilation - exposure duration deposition fraction,

with the following values:

$$
\begin{aligned}
25.5 \mathrm{mg}= & \text { nano }-\mathrm{TiO}_{2} \text { aerosol concentration } \\
& \cdot 7600 \mathrm{ml} / \mathrm{min}(8 \mathrm{hrh} / \text { day } \cdot 60 \mathrm{~min} / \mathrm{hr}) \\
& \cdot 14 \%,
\end{aligned}
$$

and therefore:

$$
\begin{aligned}
25.5 \mathrm{mg}= & \text { nano- } \mathrm{TiO}_{2} \text { aerosol concentration } \\
& \cdot 0.51 \mathrm{~m}^{3} / \text { day. }
\end{aligned}
$$

Considering both the National Institute for Occupational Safety and Health (NIOSH) and the Occupational Safety and Health Administration (OSHA) Permissible Exposure Limit $\left(0.3 \mathrm{mg} / \mathrm{m}^{3}\right.$ and $5 \mathrm{mg} / \mathrm{m}^{3}$ respectively) [4], it would require 0.34 working years or 122 working days for a human to achieve similar exposure levels to those used in this study.

\section{Conclusion}

In conclusion, the current study provides novel evidence that links acute pulmonary ENM exposure and systemic microvascular effects. Because this inflammatory link exists between the lung and the uterine microcirculation, it remains to be determined if such an axis extends to the placenta and or fetus.

\section{Materials and methods}

\section{Nanomaterial characterization}

Nano- $\mathrm{TiO}_{2}$ P25 powder, obtained from Evonik (Aeroxide $\mathrm{TiO}_{2}$, Parsippany, NJ), has previously been shown to be a mixture composed primarily of anatase $(80 \%)$ and rutile $(20 \%) \mathrm{TiO}_{2}$, with a primary particle size of $21 \mathrm{~nm}$ and a surface area of $48.08 \mathrm{~m}^{2} / \mathrm{g}$ [54], and a Zeta-potential of $-56.6 \mathrm{mV}$ [56]. Elemental composition analysis of the nano- $\mathrm{TiO}_{2}$ suspension was conducted via energy dispersive spectroscopy.

Scanning electron microscopy was performed by diluting the nano- $\mathrm{TiO}_{2} \quad 1: 100$ with filtered distilled water. $0.5 \mathrm{ml}$ of the diluted particle solution was filtered onto a $0.2 \mu \mathrm{m}$ polycarbonate filter. A wedge-shaped portion of the polycarbonate filter was mounted onto carbon double stick tape which was affixed to a $13 \mathrm{~mm}$ aluminum stub. The sample was sputter coated with gold-palladium for two minutes. The sample was imaged using a Hitachi S4800 field-emission scanning electron microscope (Tokyo, Japan).

\section{Experimental animals and exposure}

Female (8-10 weeks) Sprague - Dawley rats were purchased from Hilltop Laboratories (Scottdale, PA) and housed in an AAALAC approved facility at West Virginia University (WVU) with 12:12 h light - dark cycle and regulated temperature. Rats were allowed ad libitum access to food and water. All procedures were approved by the Institutional Animal Care and Use Committee of WVU.

$100 \mu \mathrm{g}$ of nano- $\mathrm{TiO}_{2}$ were suspended in $250 \mu \mathrm{L}$ of vehicle (Normosol and 5\% fetal bovine serum) for intratracheal instillation (IT) $24 \mathrm{~h}$ prior to experimentation. Nano- $\mathrm{TiO}_{2}$ suspensions were sonicated for $1 \mathrm{~min}$ to ensure homogenous distribution of nanoparticles. Rats were anesthetized using 5\% isoflurane and placed on a mounting stand. $250 \mu \mathrm{L}$ of the nano- $\mathrm{TiO}_{2}$ suspension was then instilled intratracheally. Sprague - Dawley rats instilled with $250 \mu \mathrm{L}$ of vehicle were used as controls.

\section{Mean arterial pressure (MAP) acquisition}

Rats were anesthetized with isoflurane gas (5\% induction, $2-3.5 \%$ maintenance). The animals were placed on a heating pad to maintain a $37{ }^{\circ} \mathrm{C}$ rectal temperature. The trachea was intubated to ensure an open airway and 
the right carotid artery was cannulated to acquire mean arterial pressure (MAP). The MAP was measured via a pressure transducer and recorded by PowerLab830 (AD Instruments, Colorado Springs, $\mathrm{CO}$ ).

\section{Multiplex cytokine panels of serum and Bronchoalveolar lavage fluid}

Whole blood (1-2 ml) was collected via tail vein puncture from exposed and control animals at time $0,1 \mathrm{~h}, 2 \mathrm{~h}$, and $4 \mathrm{~h}$ after exposure into EDTA vacutainers and centrifuged (1000 x g) to collect plasma which was flash-frozen in liquid nitrogen and stored at $-80^{\circ} \mathrm{C}$ until analysis. Rats were euthanized and tissues harvested for further analysis. Multi-spot inflammatory assays were completed per manufacturer's directions (Meso Scale Diagnostics, Rockville, MD) for: lipocalin-2, TSP-1, TIMP-1, MCP-1, interferon (IFN- $\gamma$ ), interleukin (IL)-1 $\beta$, IL-4, IL-5, IL-6, KC/GRO, IL-10, IL-13, and TNF- $\alpha$.

\section{Immunohistochemistry}

Gelatin-coated cover slips of serial tissue sections were incubated with anti-rabbit (1:100) IL-33 (Cloud-Clone Corp., Katy, TX) overnight at $4^{\circ} \mathrm{C}$, followed by 3 five-minute washes with cold PBS with $0.1 \%$ Triton-X. The sections were then incubated with a FITC conjugated goat anti-rabbit (1:100, Invitrogen, Carlsbad, CA) at $37^{\circ} \mathrm{C}$ for one hour, followed by 3 five-minute washes with cold PBS with $0.1 \%$ Triton-X. Cover slips were then mounted on slides for visualization on a Zeiss fluorescent microscope (Zeiss, Thornwood, NY).

\section{Preparation of cell suspensions}

Lungs were perfused with sterile PBS by injection into the right ventricle to remove remaining blood and then placed in PBS containing $20 \mathrm{mg} / \mathrm{ml}$ Collagenase A, $2.4 \mathrm{U} / \mathrm{ml}$ Dispase II solution, and $50 \mu \mathrm{l} / \mathrm{ml}$ DNAse (Roche, Indianapolis, IN) for $30 \mathrm{~min}$.

The lung tissue was dissociated using the gentleMACS Octo Dissociator (Miltenyi Biotec, Auburn, CA) and then centrifuged (1100 x g for $10 \mathrm{~min}$ ) to collect the sample material. The sample was resuspended with PBS and used for magnetic cell separation and flow cytometry.

\section{Flow cytometry \\ Antibodies and reagents}

ILC1 and ILC2 numbers $4 \mathrm{~h}$ after exposure to nano- $\mathrm{TiO}_{2}$ from lung tissue were determined by flow cytometry as previously described [57-59]. Briefly, ILC1 were defined as Lin-CD45 + CD161 + CD335+, while ILC2 were defined as Lin-CD45 + CD90.1 + KLRG-1 + CD25 + IL1R1 + .

Monoclonal antibodies specific for CD90.1 (FITC), KLRG1 (APC EFLUOR 780), CD25 (APC), CD161 (PERCP EFLUOR 710), and CD335 (EFLUOR 450) were purchased from eBioscience (San Diego, CA). Lineage cocktail (Lin;
ALEXA FLUOR 700) was used to gate out (CD3, CD14, CD16, CD19, CD20, and CD56: Biorad, Hercules, CA) CD3 T lymphocytes, CD14 Monocytes, CD16 NK cells, granulocytes, CD19 B lymphocytes, CD20 B lymphocytes, and CD56 NK cells. Antibodies for CD45 (Cyanine 5) were from Invitrogen (Carlsbad, CA), while those for IL1R1 (PE) where from Sino Biologicals (North Wales, PA). Flow cytometry was performed on a FACSAria (BD Bioscience, Franklin Lakes, NJ). Data were analyzed with FCS Express 6 Software (De Novo Software, Glendale, CA).

\section{Isolation of group II innate lymphoid cells}

ILC2 were isolated as per manufacturer's instructions (Miltenyi Biotec, Auburn, CA). Briefly, lineage-positive cells were indirectly labeled with a cocktail of ALEXA FLUOR 700-conjugated antibodies, as primary labeling reagent, and antibodies conjugated to MicroBeads were used as secondary labeling reagents. In the second step, lineage-negative cells were labeled with CD45, CD90.1, KLRG-1, CD25, and IL1R1, labeled with MicroBeads and isolated by positive selection from the pre-enriched lineage negative cell-fraction by separation over a MACS Column (Miltenyi Biotec, Auburn, CA), which was placed in the magnetic field of a MACS Separator. After negative selection, the cells were subsequently eluted as the positively selected cell fraction containing ILC2.

\section{Cytokine analysis of cell culture media and measurement of Phospho-NF-KB}

Isolated ILC2s were incubated $\left(37{ }^{\circ} \mathrm{C}, 90 \%\right.$ humidity, $5 \%$ $\left.\mathrm{CO}_{2}\right)$ overnight in supplemented $(10 \%$ fetal bovine serum, $1 \%$ penicillin/streptomycin, $1 \%$ sodium pyruvate, 1\% L-glutamine) Dulbecco's Modified Eagle Medium (Corning, Manassas, VA). The following day, the cell culture medium and cellular portion were separated via centrifugation (1100 x g for $10 \mathrm{~min}$ ). IL-4, IL-5, and IL-13 levels were measured in the cell culture medium via multi-spot inflammatory assays per manufacturer's directions (Meso Scale Diagnostics, Rockville, MD). Lastly, isolated cells were lysed and phospho-NF- $\mathrm{B}$ (Ser468 and Ser536) was measured (Meso Scale Diagnostics, Rockville, MD).

\section{Systemic treatment with anti-Interleukin-33 antibody}

Rats were treated $1 \mathrm{~h}$ prior to pulmonary nano- $\mathrm{TiO}_{2}$ exposure with pharmacological grade polyclonal anti-IL-33 antibody (CAT\#ABF108, EMD Millipore, Temecula, CA: intraperitoneal $1 \mathrm{mg} / \mathrm{kg}$ ). The antibody and dosage were selected based on previous murine studies [60]. The antibody used was a polyclonal anti-IL-33 antibody developed in the rabbit with specific reactivity toward mouse IL-33 and expected cross reactivity due to the close homology to rat IL-33. We determined the interspecies homology of the anti-IL-33 target between rats 
and mice to be $87 \%$ (Additional file 1: Figure S1). Plasma, bronchoalveolar lavage fluid, and lung tissue were obtained $4 \mathrm{~h}$ post-exposure from treated animals for measurement of IL-33. Uterine microvascular assessments were conducted $24 \mathrm{~h}$ after treatment in a separate cohort of animals.

\section{Pressure Myography microvessel preparation}

After measuring MAP, the uterus was removed and placed in a dissecting dish with physiological salt solution (PSS) maintained at $4{ }^{\circ} \mathrm{C}$. Radial arterioles were isolated, transferred to a vessel chamber, cannulated between two glass pipettes, and tied with silk sutures in the chamber (Living Systems Instrumentation, Burlington, VT). The chamber was superfused with fresh oxygenated $\left(5 \% \mathrm{CO}_{2} / 21 \% \mathrm{O}_{2}\right)$ PSS and warmed to $37^{\circ} \mathrm{C}$. Arterioles were pressurized to $60 \mathrm{mmHg}$ using a servo control system and extended to their in situ length. Internal and external arteriolar diameters were measured using video calipers (Colorado Video, Boulder, CO).

\section{Arteriolar reactivity}

Previous work by our group has shown that ENM exposure impacts endothelium-dependent dilation most severely within $24 \mathrm{~h}$, a condition which has been shown to improve but did not fully return to control levels after $168 \mathrm{~h}$. Based on these findings, all vascular assessments for this study were conducted $24 \mathrm{~h}$ post-exposure [30].

Arterioles were allowed to develop spontaneous tone, defined as the degree of constriction experienced by a blood vessel relative to its maximally dilated state. Vascular tone ranges from $0 \%$ (maximally dilated) to $100 \%$ (maximal constriction). Vessels with a spontaneous tone $\geq 20 \%$ less than initial tone were included in this study. After equilibration, various parameters of arteriolar function were analyzed. Vessels that did not develop sufficient spontaneous tone were not included in the data analysis.

Endothelium-Dependent Dilation - arterioles were exposed to increasing concentrations of acetyl choline (ACh: $10^{-9}-10^{-4} \mathrm{M}$ ) added to the vessel chamber.

Endothelium-Independent Dilation-increasing concentrations of sodium nitroprusside (SNP: $10^{-9}$ $10^{-4} \mathrm{M}$ ) were used to assess arteriolar smooth muscle responsiveness.

Arteriolar Vasoconstriction-arterioles were exposed to increasing concentrations of phenylephrine (PE: $10^{-9}$. $\left.10^{-4} \mathrm{M}\right)$. The steady state diameter of the vessel was recorded for at least 2 min after each dose. After each dose curve was completed, the vessel chamber was washed to remove excess chemicals by carefully removing the superfusate and replacing it with fresh warmed oxygenated PSS. After all experimental treatments were complete, the PSS was replaced with $\mathrm{Ca}^{2+}$-free PSS until maximum passive diameter was established.

\section{Pressure Myography calculations}

Data are expressed as means \pm standard error. Spontaneous tone was calculated by the following equation:

$$
\text { Spontaneous tone }(\%)=\left\{\frac{(D m-D i)}{D i}\right\} \times 100
$$

, where $\mathrm{Dm}$ is the maximal diameter and $\mathrm{Di}$ is the initial steady state diameter recorded prior to the experiment. Active responses to pressure were normalized to the maximal diameter using the following formula:

\section{Normalized diameter $=$ Dss $/ D m$}

, where Dss is the steady state diameter recorded during each pressure change. The experimental responses to $\mathrm{ACh}$, $\mathrm{PE}$, and SNP are expressed using the following equation:

$$
\begin{aligned}
& \text { Diameter (percent maximal diameter }) \\
& =\left\{\frac{(\text { Dss-Dcon })}{(\text { Dm-Dcon })}\right\} \times 100
\end{aligned}
$$

, where DCon is the control diameter recorded prior to the dose curve, DSS is the steady state diameter at each dose of the curve. The experimental response to PE is expressed using the following equation:

$$
\begin{aligned}
& \text { Diameter (percent maximal diameter }) \\
& \quad=\left\{\frac{(\text { Dcon }- \text { Dss })}{(\text { Dcon })}\right\} \times 100
\end{aligned}
$$

Wall thickness (WT) was calculated from the measurement of both inner (ID) and outer (OD) steady state arteriolar diameters at the end of the $\mathrm{Ca}^{2+}$ free wash using the following equation:

$$
W T=(O D-I D) / 2
$$

Wall-to-lumen ratio (WLR) was calculated using the following equation:

$$
W L R=W T / I D
$$

\section{Statistics}

Point-to-point differences in the dose response curves were evaluated using two-way repeated measures analysis of variance (ANOVA) with a Tukey's post-hoc analysis when significance was found. The slopes of the dose response curves were determined through a nonlinear regression. The animal characteristics, vessel characteristics and dose response curve slopes were analyzed using a one-way ANOVA with a Tukey post-hoc analysis when significance was found. All statistical analysis was completed with GraphPad Prism 5 (San Diego, CA) and SigmaPlot 11.0 (San Jose, CA). Significance was set at $p<0.05, \mathrm{n}$ is the number of arterioles, and $\mathrm{N}$ is the number of animals. 


\section{Additional file}

Additional file 1: Figure S1. IL-33 sequence homology. Multiple sequence alignment of the protein sequence of IL-33 in mice (query) and rats (subject) showing the significant interspecies homology of murine IL-33. (ZIP 259 kb)

\section{Abbreviations}

ACh: Acetylcholine; ANOVA: Analysis of variance; APC: Allophycocyanin; BALF: Broncho alveolar lavage fluid; CD: Cluster of differentiation; Dcon: Control diameter; Di: Initial diameter; Dm: Maximal diameter; Dss: Steady state diameter; EDTA: Ethylenediaminetetraacetic acid; ENM: Engineered nanomaterials; FITC: Fluorescein isothiocyanate; ID: Inner diameter; IFN-y: Interferon-gamma; IL: Interleukin; ILC: Innate lymphoid cells; KC/GRO: Keratinocyte chemoattractant/human growth-regulated oncogene; KLRG-1: Killer cell lectin-like receptor subfamily G member 1; Lin: Lineage; MCP-1: Monocyte chemoattractant protein 1; $\mathrm{Nano}_{-} \mathrm{TiO}_{2}$ : Titanium dioxide nanoparticles; NF-kB: Nuclear factor kappa-light-chain-enhancer of activated B cells; NIOSH: National Institute for Occupational Safety and Health; NK: Natural Killer; NO: Nitric oxide: OD: Outer diameter; OSHA: Occupational Safety and Health Administration; PBS: Phosphate buffered saline; PE: Phenylephrine; PE: Phycoerythrin; SEM: Scanning electron microscope; SEM: Standard error of the mean; Ser-468: Serine-468; SNP: Sodium nitroprusside; ST2: Suppressor of tumor tumorigenicity; Th2: T-helper type 2; TIMP-1: Tissue inhibitor of metalloproteinases 1; TNF- a: Tumor necrosis factor alpha; TSP-1: Thrombospondin 1; WLR: Wall-to-lumen ratio; WT: Wall thickness

\section{Acknowledgments}

We thank Kevin Engels from the West Virginia University (WVU) Department of Physiology and Pharmacology for his technical assistance in this study, and Dr. Kathleen Brundage from the Flow Cytometry \& Single Cell Core Facility at WVU (FORTESSA S10 OD016165, FACSAria S10 RR020866). In addition, we would like to acknowledge our financial support: R01-ES015022 (TRN), and NSF-1003907 (TRN and ABA).

\section{Availability of data and materials}

All data generated or analyzed during this study are included in this published article [and its supplementary information files.

\section{Disclaimer}

The findings and conclusions in this report are those of the author(s) and do not necessarily represent the official position of the National Institute for Occupational Safety and Health, Centers for Disease Control and Prevention.

\section{Authors' contributions \\ ABA conducted the vascular and immunological assessments, analyzed and interpreted the data, and was a major contributor in writing the manuscript. CRM assisted with the vascular assessments and was involved in drafting the manuscript and revising it critically for important intellectual content. TPB performed the tracheal immunohistochemistry and was involved in drafting the manuscript. WTG was involved in the animal exposures and was involved in the drafting of the manuscript. ECB and KLG were involved in the analysis and interpretation of the data and were major contributors in writing the manuscript. SF obtained the SEM images of the nano- $\mathrm{TiO}_{2}$ and was involved in drafting of the manuscript. TRN made substantial contributions to the conception and design of the experiments, analysis and interpretation of the data and was a major contributor in writing of the manuscript. All the authors read and approved the final manuscript}

\section{Ethics approval and consent to participate} Not applicable.

\section{Competing interests}

The authors declare that they have no competing interests.

\section{Publisher's Note}

Springer Nature remains neutral with regard to jurisdictional claims in published maps and institutional affiliations.

\section{Author details}

'Department of Physiology and Pharmacology, West Virginia University School of Medicine, 64 Medical Center Drive, Robert C. Byrd Health Sciences Center - West Virginia University, Morgantown, WV 26505-9229, USA.

${ }^{2}$ Toxicology Working Group, West Virginia University School of Medicine, Morgantown, WV, USA. ${ }^{3}$ National Institute for Occupational Safety and Health, Morgantown, WV, USA.

Received: 7 June 2018 Accepted: 24 October 2018

Published online: 09 November 2018

\section{References}

1. Jackson P, et al. Prenatal exposure to carbon black (printex 90): effects on sexual development and neurofunction. Basic Clin Pharmacol Toxicol. 2011; 109(6):434-7.

2. Johansson HKL, et al. Airway exposure to multi-walled carbon nanotubes disrupts the female reproductive cycle without affecting pregnancy outcomes in mice. Part Fibre Toxicol. 2017;14(1):17.

3. Stapleton PA, et al. Maternal engineered nanomaterial exposure and fetal microvascular function: does the barker hypothesis apply? Am J Obstet Gynecol. 2013;209(3):227 e1-11.

4. Stapleton PA, et al. Maternal engineered nanomaterial inhalation during gestation alters the fetal transcriptome. Part Fibre Toxicol. 2018;15(1):3.

5. Engler-Chiurazzi EB, et al. Impacts of prenatal nanomaterial exposure on male adult Sprague-Dawley rat behavior and cognition. J Toxicol Environ Health A. 2016:79(11):447-52.

6. McKenzie AN. Type-2 innate lymphoid cells in asthma and allergy. Ann Am Thorac Soc. 2014;11(Suppl 5):S263-70.

7. Sonnenberg GF, et al. SnapShot: innate lymphoid cells. Immunity. 2013; 39(3):622-622 e1.

8. Artis D, Spits H. The biology of innate lymphoid cells. Nature. 2015; 517(7534):293-301.

9. Turner JE, et al. IL-9-mediated survival of type 2 innate lymphoid cells promotes damage control in helminth-induced lung inflammation. J Exp Med. 2013:210(13):2951-65.

10. Vercelli D, Gozdz J, von Mutius E. Innate lymphoid cells in asthma: when innate immunity comes in a Th2 flavor. Curr Opin Allergy Clin Immunol. 2014;14(1):29-34.

11. Spits $H$, et al. Innate lymphoid cells--a proposal for uniform nomenclature. Nat Rev Immunol. 2013;13(2):145-9.

12. Takatori $\mathrm{H}$, et al. Lymphoid tissue inducer-like cells are an innate source of IL-17 and IL-22. J Exp Med. 2009:206(1):35-41.

13. Yasuda K, et al. Contribution of IL-33-activated type II innate lymphoid cells to pulmonary eosinophilia in intestinal nematode-infected mice. Proc Natl Acad Sci U S A. 2012;109(9):3451-6.

14. Shaw $\mathrm{J}$, et al. IL-33-responsive innate lymphoid cells are an important source of IL-13 in chronic rhinosinusitis with nasal polyps. Am J Respir Crit Care Med. 2013;188(4):432-9.

15. Marsland BJ, et al. Innate signals compensate for the absence of PKC-\{theta\} during in vivo CD8(+) T cell effector and memory responses. Proc Natl Acad Sci U S A. 2005;102(40):14374-9.

16. Katwa $P$, et al. A carbon nanotube toxicity paradigm driven by mast cells and the IL-(3)(3)/ST(2) axis. Small. 2012:8(18):2904-12

17. Wang $X$, et al. Intravenously delivered graphene nanosheets and multiwalled carbon nanotubes induce site-specific Th2 inflammatory responses via the IL-33/ST2 axis. Int J Nanomedicine. 2013;8:1733-48.

18. Wang $X$, et al. Multi-walled carbon nanotube instillation impairs pulmonary function in C57BL/6 mice. Part Fibre Toxicol. 2011;8:24

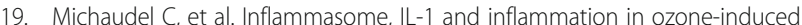
lung injury. Am J Clin Exp Immunol. 2016;5(1):33-40.

20. Beamer CA, et al. IL-33 mediates multi-walled carbon nanotube (MWCNT)induced airway hyper-reactivity via the mobilization of innate helper cells in the lung. Nanotoxicology. 2013;7(6):1070-81.

21. Kabata H, et al. Group 2 innate lymphoid cells and asthma. Allergol Int. 2015:64(3):227-34

22. Hams E, Fallon PG. Innate type 2 cells and asthma. Curr Opin Pharmacol. 2012;12(4):503-9.

23. Deckers J, Branco Madeira F, Hammad H. Innate immune cells in asthma. Trends Immunol. 2013;34(11):540-7.

24. Lai DM, Shu Q, Fan J. The origin and role of innate lymphoid cells in the lung. Mil Med Res. 2016;3:25. 
25. Ley K. The second touch hypothesis: T cell activation, homing and polarization. F1000Res. 2014;3:37.

26. Halim TYF, McKenzie ANJ. New kids on the block: group 2 innate lymphoid cells and type 2 inflammation in the lung. Chest. 2013;144(5):1681-6.

27. Głobińska A, Kowalski ML. Innate lymphoid cells: The role in respiratory infections and lung tissue damage. Expert Rev Clin Immunol. 2017;13(10):991-9.

28. Pugazhenthi $\mathrm{S}$, et al. Induction of an inflammatory loop by interleukin-1 beta and tumor necrosis factor-alpha involves NF-kB and STAT-1 in differentiated human neuroprogenitor cells. PLoS One. 2013;8(7):e69585.

29. Pradere JP, et al. Negative regulation of NF-kappaB p65 activity by serine 536 phosphorylation. Sci Signal. 2016;9(442):ra85.

30. Stapleton PA, et al. Impairment of coronary arteriolar endotheliumdependent dilation after multi-walled carbon nanotube inhalation: a timecourse study. Int J Mol Sci. 2012;13(11):13781-803.

31. Schmitz J, et al. IL-33, an interleukin-1-like cytokine that signals via the IL-1 receptor-related protein ST2 and induces T helper type 2-associated cytokines. Immunity. 2005;23(5):479-90.

32. Zeng $\mathrm{S}$, et al. IL-33 receptor (ST2) Signalling is important for regulation of Th2-mediated airway inflammation in a murine model of acute respiratory syncytial virus infection. Scand J Immunol. 2015;81(6):494-501.

33. Mjosberg JM, et al. Human IL-25- and IL-33-responsive type 2 innate lymphoid cells are defined by expression of CRTH2 and CD161. Nat Immunol. 2011;12(11):1055-62.

34. Zoltowska AM, et al. The interleukin-33 receptor ST2 is important for the development of peripheral airway hyperresponsiveness and inflammation in a house dust mite mouse model of asthma. Clin Exp Allergy. 2016;46(3):479-90.

35. Stier MT, et al. IL-33 promotes the egress of group 2 innate lymphoid cells from the bone marrow. J Exp Med. 2018;215(1):263-81.

36. Nurkiewicz TR, et al. Nanoparticle inhalation augments particle-dependent systemic microvascular dysfunction. Part Fibre Toxicol. 2008;5:1.

37. Abukabda $\mathrm{AB}$, et al. Heterogeneous vascular bed responses to pulmonary titanium dioxide nanoparticle exposure. Front Cardiovasc Med. 2017;4:33.

38. Stapleton $\mathrm{PA}$, et al. Uterine microvascular sensitivity to nanomaterial inhalation: an in vivo assessment. Toxicol Appl Pharmacol. 2015;288(3):420-8.

39. Stapleton PA, et al. Estrous cycle-dependent modulation of in vivo microvascular dysfunction after nanomaterial inhalation. Reprod Toxicol. 2018:78:20-8.

40. LeBlanc AJ, et al. Nanoparticle inhalation impairs endothelium-dependent vasodilation in subepicardial arterioles. J Toxicol Environ Health A. 2009; 72(24):1576-84.

41. Spits H, Di Santo JP. The expanding family of innate lymphoid cells: regulators and effectors of immunity and tissue remodeling. Nat Immunol. 2011:12(1):21-7.

42. Hams E, et al. IL-25 and type 2 innate lymphoid cells induce pulmonary fibrosis. Proc Natl Acad Sci U S A. 2014;111(1):367-72.

43. Monticelli LA, et al. Innate lymphoid cells promote lung-tissue homeostasis after infection with influenza virus. Nat Immunol. 2011;12(11):1045-54.

44. Pichery $\mathrm{M}$, et al. Endogenous IL-33 is highly expressed in mouse epithelial barrier tissues, lymphoid organs, brain, embryos, and inflamed tissues: in situ analysis using a novel II-33-LacZ gene trap reporter strain. J Immunol. 2012;188(7):3488-95.

45. Sanfins $E$, et al. Nanoparticle effect on neutrophil produced myeloperoxidase. PLoS One. 2018;13(1):e0191445.

46. Thompson EA, et al. Innate immune responses to nanoparticle exposure in the lung. J Environ Immunol Toxicol. 2014;1(3):150-6.

47. Taylor AJ, et al. Atomic layer deposition coating of carbon nanotubes with aluminum oxide alters pro-fibrogenic cytokine expression by human mononuclear phagocytes in vitro and reduces lung fibrosis in mice in vivo. PLoS One. 2014;9(9):e106870

48. Bonner JC, Hoffman M, Brody AR. Alpha-macroglobulin secreted by alveolar macrophages serves as a binding protein for a macrophage-derived homologue of platelet-derived growth factor. Am J Respir Cell Mol Biol. 1989:1(3):171-9.

49. Look M, et al. The nanomaterial-dependent modulation of dendritic cells and its potential influence on therapeutic immunosuppression in lupus. Biomaterials. 2014;35(3):1089-95.

50. Xu J, et al. IL33-mediated ILC2 activation and neutrophil IL5 production in the lung response after severe trauma: a reverse translation study from a human cohort to a mouse trauma model. PLoS Med. 2017;14(7):e1002365
51. Yang $Q$, et al. Group 2 innate lymphoid cells mediate ozone-induced airway inflammation and hyperresponsiveness in mice. J Allergy Clin Immunol. 2016;137(2):571-8.

52. Yoda K, et al. Stochastic secretion response to transient stimulus of Goup-2 innate lymphoid cells (ILC2). Nagoya: IEEE; 2017. https://ieeexplore.ieee.org/ document/8305219.

53. Baisch BL, et al. Equivalent titanium dioxide nanoparticle deposition by intratracheal instillation and whole body inhalation: the effect of dose rate on acute respiratory tract inflammation. Part Fibre Toxicol. 2014;11:5.

54. Nurkiewicz TR, et al. Pulmonary nanoparticle exposure disrupts systemic microvascular nitric oxide signaling. Toxicol Sci. 2009:110(1):191-203.

55. Stone KC, et al. Distribution of lung cell numbers and volumes between alveolar and nonalveolar tissue. Am Rev Respir Dis. 1992;146(2):454-6.

56. Nichols $\mathrm{CE}$, et al. Reactive oxygen species damage drives cardiac and mitochondrial dysfunction following acute nano-titanium dioxide inhalation exposure. Nanotoxicology. 2018;12(1):32-48.

57. Drake LY, Kita H. Group 2 innate lymphoid cells in the lung. Adv Immunol. 2014;124:1-16.

58. Duerr CU, Fritz JH. Isolation of group 2 innate lymphoid cells from mouse lungs. Methods Mol Biol. 2017;1656:253-61.

59. Halim TY, Takei F. Isolation and characterization of mouse innate lymphoid cells. Curr Protoc Immunol. 2014;106:3 25 1-13.

60. Liu X, et al. Anti-LL-33 antibody treatment inhibits airway inflammation in a murine model of allergic asthma. Biochem Biophys Res Commun. 2009; 386(1):181-5.

\section{Ready to submit your research? Choose BMC and benefit from:}

- fast, convenient online submission

- thorough peer review by experienced researchers in your field

- rapid publication on acceptance

- support for research data, including large and complex data types

- gold Open Access which fosters wider collaboration and increased citations

- maximum visibility for your research: over $100 \mathrm{M}$ website views per year

At BMC, research is always in progress.

Learn more biomedcentral.com/submissions 